\title{
Impact of SARS-CoV-2 Infection on Patients Suffering from Liver Injury
}

\author{
Ashish Kumar Vyas Anirudh Singh \\ Department of Microbiology, All India Institute of Medical Sciences, Bhopal, India
}

\section{Dear Editor,}

With great interest, we have read the recent article by Anastasioua et al. [1], wherein the authors described the effect of SARS-CoV-2 infection on mortality in patients suffering from Mild or severe liver injury. They demonstrated that while the mild liver injury was not associated with worse outcome in their cohort, cohart with severe liver injury showed multiple-organ failure and acute vascular events [1] leading to higher mortality.

While the findings of study are intriguing, we have few concerns about the study design as well as few suggestions which would bring better insight to the study.

1. Acute liver failure is a rare condition in which massive liver injury is associated with the rapid development of hepatic encephalopathy increasing the mortality in this group of patients $[2,3]$. In the present study, it is very difficult to conclude that the death rate is higher in group 3 due to the infection of SARS-CoV-2.

2. Present study would have been more impactful if authors included ALF patients without SARS-CoV-2 infection.

3. The severity due to SARS-CoV-2 infection in majority of cases is directly propostional to blood oxygen satutration levels $\left(\mathrm{SpO}_{2}\right)$ [4]. However, the authors did not investigated it. This may have provided a better understanding of role of SARS-CoV-2 infection in the higher moratlity rate among the groups.
4. It is surprizing that authors did not discussed the aetiology of ALF patients such as viral hepatitis, Alcoholic hepatitis, Autoimmune hepatitis, Wilson disease, or sepsis etc. The mortality rate in ALF patients varies and dependent upon multiple factors such as aetiology, age, sex, and supportive care [5].

5. Authors classified patient on the basis of ALT and bilirubin levels but there is significant variation of age among the groups and the consequence of this variation is not discussed.

However, we agree with the authors that the fate of COVID-19 majorly depends on the comorbidity and age of the infected patients.

\section{Conflict of Interest Statement}

The authors have no conflicts of interest to declare.

\section{Funding Sources}

Department of Science and Technology, Govt. of India. Grant No. [DST/INSPIRE/04/2018/000019]. 


\section{References}

Liver Disease and SARSCoV-2 Infection
1 Anastasiou OE, Korth J, Herbstreit F, Witzke $\mathrm{O}$, Lange CM. Mild vs. severe liver injury in SARS-CoV-2 infection. Dig Dis. 2020 Aug 10: $1-6$.

2 Akamatsu N, Sugawara Y, Kokudo N. Acute liver failure and liver transplantation. Intractable Rare Dis Res. 2013;2(3):77-87.

3 Panackel C, Thomas R, Sebastian B, Mathai SK. Recent advances in management of acute liver failure. Indian J crit Care Med. 2015; 19(1):27-33.
4 Shenoy N, Luchtel R, Gulani P. Considerations for target oxygen saturation in COVID-19 patients: are we under-shooting? BMC Med. 2020;18(1):260.

5 Marudanayagam R, Shanmugam V, Gunson B, Mirza DF, Mayer D, Buckels J, et al. Aetiology and outcome of acute liver failure. HPB. 2009;11(5):429-34. 